\title{
Assessing the Performance of a Hydrological Tank Model at Various Spatial Scales
}

\author{
Mehdi Sheikh Goodarzi, ${ }^{1}$ Bahman Jabbarian Amiri, ${ }^{1}$ Hossein Azarneyvand, ${ }^{1}$ Manoochehr Khazaee ${ }^{2}$ and \\ Nadjmeh Mahdianzadeh ${ }^{1}$ \\ ${ }^{1}$ University of Tehran, Tehran, Iran; ${ }^{2}$ University of Pittsburgh, Pittsburgh, Pennsylvania.
}

\begin{abstract}
In this study we investigated the performance of the Tank hydrologic model in predicting rainfall-runoff using a descriptive-analytical approach, including objective error measures and flow signatures (mean annual specific runoff, mean flow duration curves, normalized low flow and high flow indexes, coefficient of variation, and hydrograph flashiness). Because hydrological processes vary at different scales, three watersheds located in three significantly different environments, which are examples of small (15 $\left.\mathrm{km}^{2}\right)$, medium $\left(215 \mathrm{~km}^{2}\right)$ and large $\left(542 \mathrm{~km}^{2}\right)$ watersheds, were selected to evaluate the performance of the hydrologic model.

We found that Neka (the small watershed) has a large water budget with a steep flow slope, including both extremely low flow (lowest) and high flow (highest), a very high variation, and a flashy hydrograph $(0.21 \leq \mathrm{HF} \leq 0.41)$. Ghezel-Ozan (the medium watershed) also has a large water budget with a fairly steep flow slope, an extremely low flow and a moderate high flow, a moderate variation, and a very steady hydrograph $(0.01 \leq \mathrm{HF} \leq 0.02)$. Babolroud (the large watershed) possesses a moderate water budget with a moderate flow slope, a below-average low flow, a moderate high flow, an average variation, and a fairly flashy hydrograph $(0.22 \leq \mathrm{HF} \leq 0.28)$.

The quality of rainfall-runoff modeling was good to satisfactory for the medium and large watersheds as shown by the two error metrics $(1.32 \leq \mathrm{RMSE} \leq 2.58,0.61 \leq \mathrm{NSE} \leq 0.8)$. However, the small watershed performance, especially in the validation period, was unsatisfactory $(4.66 \leq \mathrm{RMSE} \leq 5.33,0.21 \leq \mathrm{NSE} \leq 0.51)$. The limitations identified should be considered for medium watersheds. The Tank model is highly recommended for use in hydrologic predictions of large watersheds.
\end{abstract}

\section{Introduction}

Distributed and semi-distributed hydrologic models explicitly consider spatial variability, which lumped models neglect (Khakbaz et al. 2012). Distributed modeling requires extensive data (Amiri et al. 2019); thus it can only be used for watersheds with sufficient available data. Generating surface flow components relies on hydro-climatic data as well as hydraulic attributes of watersheds (Reed et al. 2004). Because they use numerical methods in the discretization of physically-based models, these models are operated in a distributed form. If the equations governing the rainfall-runoff process are correctly configured, most of the hydrologic parameters can be predicted through the physical properties of the watershed such as area, soil, geology and vegetation cover. Consequently, such an approach can help to reduce the sensitivity of optimization processes in the distributed models (measuring rather than optimization). Due to the extent of data required and the long runtimes of distributed models, use of these models will probably be impossible if source data is restricted or limited (Reed et al. 2004; Amiri et al. 2016).
This study used the Tank model, which takes advantage of conceptual model capabilities (Ekenberg 2016; Patil and Stieglitz 2014; Haberlandt and Radtke 2014). Elimination of the complexity of conceptualizing hydrological responses, acquiring acceptable results, and minimum data requirements are the advantages of the lumped models that motivate hydrologic modelers to consider these models as efficient and parsimonious platforms, especially in data deficit conditions (Amiri et al. 2019; Sheikh Goodarzi, Navardi et al. 2018). On the other hand, the Tank model, which was introduced by Sugawara et al. (1984) in Japan, is one of the most frequently used conceptual models (Franchini and Pacciani, 1991; Aqili et al. 2016; Sugiura et al. 2016; Ou et al. 2017). Furthermore, the relative simplicity of the concepts, calculations, and accurate predictions of hydrological processes in watersheds in various climates are attractive features of the Tank model (see Table 1), which is recommended over other models. The assumptions of the Tank model are that a given watershed is a set of related tanks (Sheikh Goodarzi, Jabbarian Amiri et al. 2018). It should be mentioned that the model structure and a suitable method have a direct influence on the performance of

Sheikh Goodarzi, Mehdi, Bahman Jabbarian Amiri, Hossein Azarneyvand, Manoochehr Khazaee and Nadjmeh Mahdianzadeh. "Assessing the Performance of a Hydrological Tank Model at Various Spatial Scales." Journal of Water Management Modeling 29: C472. doi: 10.14796/JWMM.C472.

(C) CHI 2020. www.chijournal.org ISSN 2292-6062. 
these models. Due to the importance of calibration in conceptual models, many procedures, varying from trial and error to sophisticated automated methods, have been developed to calibrate the parameters (Ahmadian and Sheikh Goodarzi 2014). Automatic calibration methods can also be used by using optimization techniques to determine hydrologic parameters.

Selecting an appropriate search algorithm in general, and choosing a proper objective function in particular, can demonstrate how well the optimization process works (Nash and Sutcliffe 1970). The root mean square error (RMSE) has been widely used. When error propagation follows a Gaussian distribution and the sample dataset is sufficiently large, RMSE is superior to other objective functions (Chai and Draxler 2014). The NashSutcliffe efficiency (NSE) metric, a normalized statistic, is another important and widely used objective function which estimates modeling noise (the magnitude of residual relative variance) from an observed series (Nash and Sutcliffe 1970). To provide a better understanding of the rainfall-runoff process, performing investigations such as this study is necessary, particularly when the data are scarce.

Table 1 Comparative performance of Tank, SIMHYD and AWBM conceptual hydrologic models in an experimental watershed in Iran (Sheikh Goodarzi, Jabbarian Amiri et al. 2018).

\begin{tabular}{cccc}
\hline Hydrologic model & Calibration & $\begin{array}{c}\text { Evaluation criteria } \\
\text { Pearson correlation } \\
\text { coeficcient }(r)\end{array}$ & NSE \\
\hline TANK & Calibration & 0.85 & 0.72 \\
SIMHYD & & 0.77 & 0.60 \\
AWBM & & 0.77 & 0.59 \\
TANK & Validation & 0.92 & 0.84 \\
SIMHYD & & 0.84 & 0.71 \\
AWBM & & 0.89 & 0.80 \\
\hline
\end{tabular}

\section{Methodology}

\subsection{Study Area}

This study was conducted to investigate the capability of the Tank hydrologic model in the simulation of hydrological processes, in temperate and humid regions. Since watershed area is one of the most important factors influencing hydrological processes (Beven and Binley 2014), three watersheds along the southern shore of the Caspian Sea were chosen as being representative of small (first quartile), medium (second quartile) and large (third quartile) watersheds: Neka $\left(36.76^{\circ} \mathrm{N}, 53.25^{\circ} \mathrm{E} ; 15 \mathrm{~km}^{2}\right)$, Ghezel-Ozan $\left(36.80^{\circ} \mathrm{N}, 49.70^{\circ} \mathrm{E} ; 215 \mathrm{~km}^{2}\right)$ and Babolroud $\left(36.40^{\circ} \mathrm{N}, 52.64^{\circ} \mathrm{E}\right.$; $542 \mathrm{~km}^{2}$ ) (Figure 1).

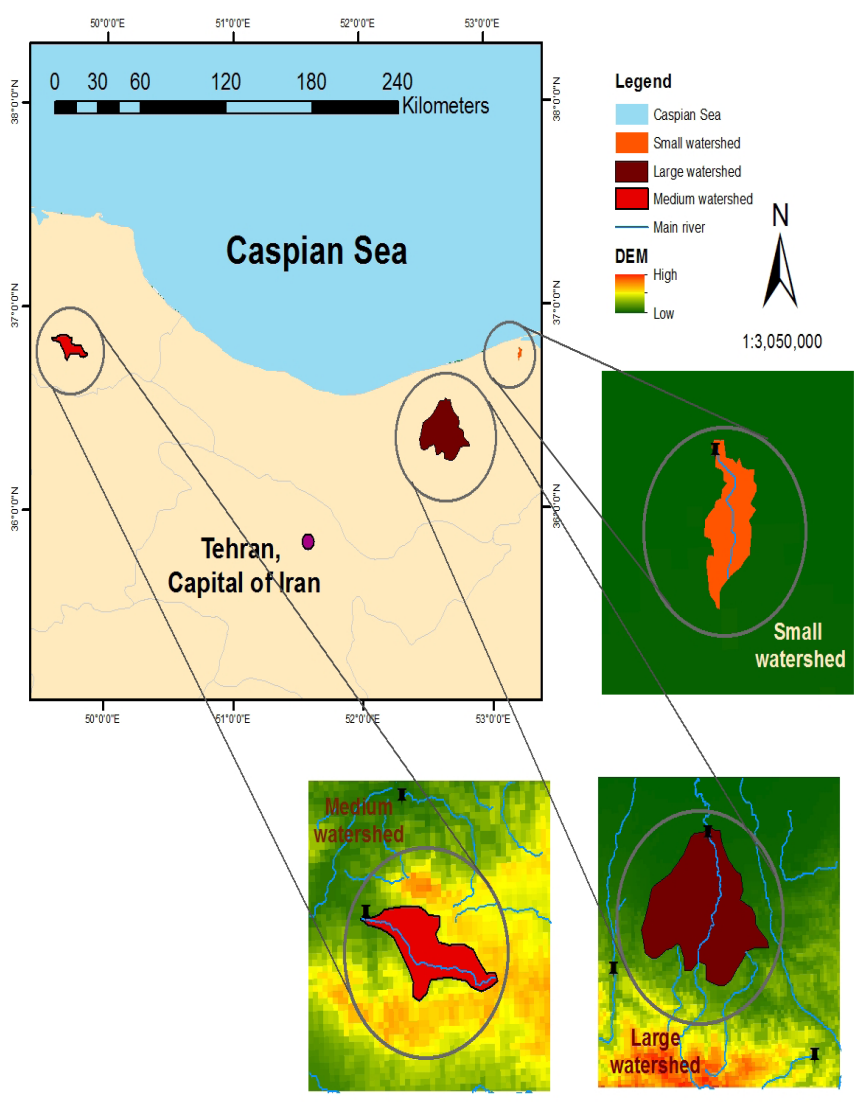

Figure 1 Locations of the Neka 13006, Qezel-Ozan 17033 and Babolroud 14017 watersheds (including positions of gauges, main stream, and upstream watershed boundary).

The watersheds are mainly in low-slope regions ( $<15 \%)$ with elevations ranging from $15 \mathrm{~m}$ to $1227 \mathrm{~m}$ above sea level. During the modeling period (2001-2011), the average rainfall, temperature, and discharge height of the watersheds were respectively $1.35 \mathrm{~mm}-1.95 \mathrm{~mm}$ (standard deviation, SD, 5.16-5.66), $15.38^{\circ} \mathrm{C}-17.45^{\circ} \mathrm{C}$ (SD 5.16-5.66), and $1.16 \mathrm{~mm}-2.06 \mathrm{~mm}$ (SD $1.87-5.82)$. Land coverage over most parts of Neka is agricultural (96\%); Qezel-Ozan is principally covered by rangeland (61\%) and forest (38\%); and Babolroud is mostly covered by agricultur3e $(53 \%)$ and forest (42\%). It should be mentioned that $<5 \%$ of all watersheds are covered by urban (i.e. impervious surfaces are rare; Sheikh Goodarzi 2013).

\subsection{Tank Hydrologic Model}

The Tank hydrologic model is a flexible platform designed to represent different sorts of watershed, with conditions from entirely impervious (urbanized) to densely forested areas. According to the physical and ecological structure of the study sites (land coverage), we adopted a framework that consists of four tanks (Sugawara et al. 1984).

The highly forested Tank model is composed of four separate and perpendicularly inter-connected tanks representing 
infiltration (P1), percolation (P6) and deep percolation (P9) flows into lower soil layers (Figure 2). The height of water in the four tanks is controlled by four parameters: P3 (outlet height of subbase flow from the first tank), P4 (outlet height of surface flow from the first tank), P8 (outlet height of intermediate flow from the second tank), and P11 (outlet height of subbase flow from the third tank). Upon a rainfall event, infiltration and evaporation occur simultaneously in the first tank (Sugawara et al. 1984; Ou et al. 2017). The evaporated part of the rainfall is first collected from the upper tank. Compensatory amounts of water are supplied from the second, third and fourth tanks. In case of emergencies, this process will be continued until the fourth tank is discharged.

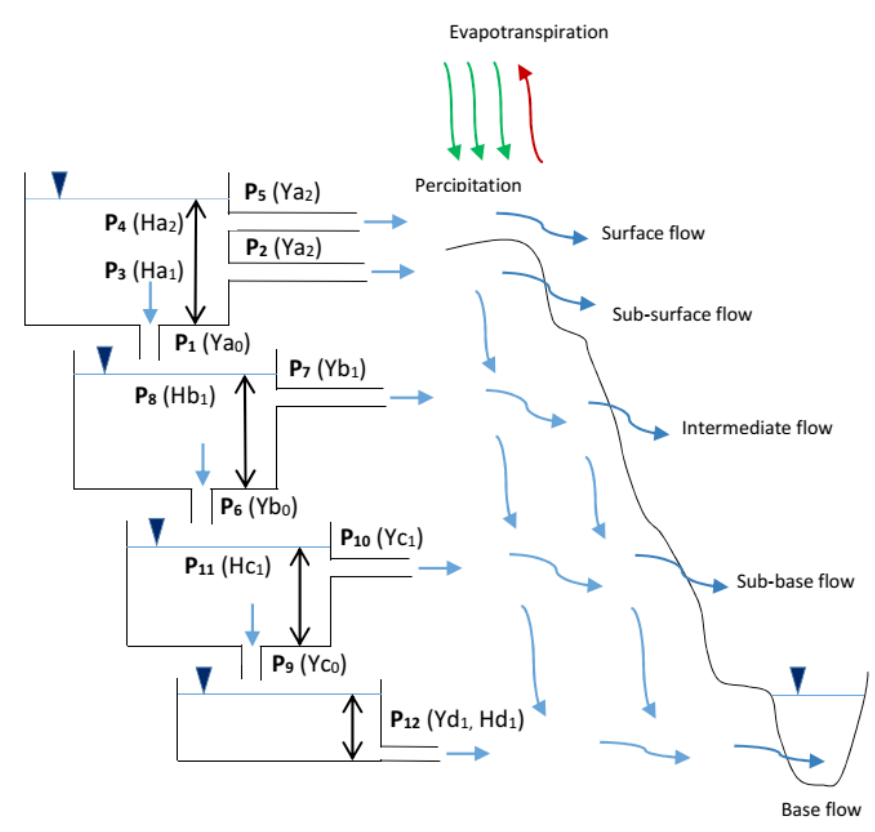

Figure 2 Structure of a typical Tank model for forested areas.

When water storage is increasing, excess water content is considered as runoff from the tank. The outflows from the four tanks are surface flow P5, subsurface flow P2, intermediate flow P7, subbase flow P10, and base flow P12 (Amiri et al. 2016). Figure 2 shows the parameters and main components of a generic Tank model (more details are given in Sheikh Goodarzi, Navardi et al. 2018).

\section{Data Requirements}

Execution of the hydrologic models mainly depends on data availability. Since the aim of this study is to assess the Tank performance over different spatial scales, especially under data deficient conditions, the lumped structure of the Tank was selected as a hydrologic platform.

For this purpose, hydrometric data including daily rainfall $(P, \mathrm{~mm})$ and discharge $(Q, \mathrm{~mm})$ were obtained from the Water Resource Management Company of Iran (WRM.ir). Climatological records containing surface temperature $\left({ }^{\circ} \mathrm{C}\right)$ and solar radiation were also compiled from the National Meteorological Organization (NMO.ir).

Collected data were comprehensively investigated to ensure data quality. Missed or incomplete data were substituted by averaging.

All datasets were transformed to the same daily and height formats by dividing the discharge volume of a given catchment by its area (Sheikh Goodarzi 2013). Actual evapotranspiration was calculated using Hargreaves's potential evapotranspiration and crop coefficients, which have been used in previous studies (Allen et al. 1998; Verstraeten et al. 2005; Amiri et al. 2016; Amiri et al. 2019).

\subsection{Calibration}

The Tank model was calibrated using the optimization approach suggested by Setiawan et al (2007). For this purpose, water balance components were optimized using equations 1 and 2 where $R, E, Q$, and $Y$ are rainfall, evapotranspiration, runoff and lateral flows. $H_{a}$ stands for the water head and $Y_{a 1^{\prime}}, Y_{a 2^{\prime}} Y_{b 1^{\prime}}, Y_{c 1}$ and $Y_{d 1}$ are respectively sub-surface flow, surface flow, intermediate flow, subbase flow and base flow.

$$
\begin{aligned}
& \frac{d H_{a}}{d t}=R-E-Q \\
& Q=\left(Y_{a 1}+Y_{a 2}+Y_{b 1}+Y_{c 1}+Y_{d 1}\right)
\end{aligned}
$$

RMSE and NSE were selected as the basis for choosing the optimal simulated outputs. Additional watershed indexes, mean annual specific runoff (MASR), the slope of the flow duration curve (mFDC), the normalized low flow statistic (NLF), the normalized high flow statistic (NHF), the coefficient of variation (CV), and hydrograph flashiness (HF), were calculated to evaluate the performance of the Tank model by providing analytical descriptors.

The datasets were divided into two parts for calibration (70\%) and validation (30\%) prior to modeling. In each period, a small selection of records, equal to $10 \%$ of the initial input data, was considered as warm-up and was not used in the overall performance evaluation.

\section{Objective Functions}

NSE and RMSE were used as metrics to evaluate the performance of the hydrologic model (Nash and Sutcliffe 1970; Chai and Draxler 2014). NSE values range from $-\infty$ to +1 and they index the quality of the modeling procedure. Values of $<0.5,0.5-0.7$ and $>0.7$ were respectively considered as unsatisfactory, satisfactory and good (Ketabchy et al. 2018). The relationship between RMSE and modeling performance is such that lower values of RMSE represent a better modeling performance. Values $<5$ or, ideally, $<1$ are preferred according to the literature reviewed (Sheikh Goodarzi 2013). 


\section{Catchment Characteristics}

Equations 3-8, which analytically describe the discharge of a given watershed, are used to calculate the catchment characteristics (Viglione et al. 2013; USGS 2008):

$$
\begin{aligned}
& M A S R=365 \times \bar{Q}_{d}=\frac{365}{T} \sum_{t=1}^{T} Q_{d}(t) \\
& m F D C=100 \times \frac{Q_{25 \%}-Q_{75 \%}}{50 \times \bar{Q}_{d}} \\
& n Q_{95}=\frac{Q_{95 \%}}{\bar{Q}_{d}} \\
& n Q_{05}=\frac{Q_{05 \%}}{\bar{Q}_{d}} \\
& C V=\frac{S_{Q d}}{\bar{Q}_{d}} \\
& H F=1-r_{e, f}
\end{aligned}
$$

where:

$$
\begin{aligned}
\bar{Q}_{d} & =\text { mean annual daily discharge, } \\
Q_{k \%} & =\text { flow quantiles ( } k=05 \%, 25 \%, 75 \% \text { or } 95 \%), \\
n & =\text { normalized form of } Q_{k \%} \\
S_{Q d} & =\text { standard deviation of annual daily discharge (SD), } \\
r & =\text { linear auto-correlation coefficient, } \\
e & =1 \text { d delayed observed daily discharge, and } \\
f & =1 \text { d delayed predicted discharge. }
\end{aligned}
$$

Mean annual specific runoff ( $M A S R, \mathrm{~mm})$ is the mean discharge and is an indicator of annual flow; $m F D C$ is a measure of the slope of the central part of the flow duration curve and indicates increase in runoff as a percentage of the annual mean for a $1 \%$ decrease in exceedance probability.

The normalized low flow statistic $\left(n Q_{95 \%}\right)$ indicates the extent of low flow in a watershed. It is normalized by mean annual runoff so that $95 \%$ of the recorded discharges are $>n Q_{95 \%}$. The normalized high flow statistic $\left(n Q_{05 \%}\right)$ is an indicator of high flow in a watershed. This statistic is normalized by mean annual runoff in a way such that $95 \%$ of the recorded discharges are $<n Q_{05 \%}$. The coefficient of variation $(\mathrm{CV})$ represents major variation in flow during the study period. Hydrograph flashiness (HF) indicates the velocity of fluctuations in the hydrological processes of the watersheds, such as the apparent variations in daily discharge.

\begin{tabular}{|c|c|c|c|c|c|c|c|c|c|c|c|c|}
\hline Criteria & P1 & P2 & P3 & P4 & P5 & P6 & P7 & P8 & P9 & P10 & P11 & P12 \\
\hline \multicolumn{13}{|l|}{ Small Watershed } \\
\hline Max. & 0.28 & 1.00 & 98.09 & 99.91 & 1.00 & 1.00 & 1.00 & 99.75 & 1.00 & 1.00 & 99.94 & 1.00 \\
\hline Avg. & 0.15 & 0.67 & 55.77 & 58.81 & 0.43 & 0.51 & 0.48 & 49.38 & 0.51 & 0.48 & 46.86 & 0.52 \\
\hline Min. & 0.00 & 0.19 & 28.86 & 1.47 & 0.00 & 0.00 & 0.00 & 1.14 & 0.00 & 0.00 & 1.33 & 0.00 \\
\hline SD & 0.06 & 0.22 & 13.20 & 26.72 & 0.29 & 0.28 & 0.30 & 28.74 & 0.28 & 0.28 & 29.58 & 0.28 \\
\hline Calibrated value & 0.14 & 0.69 & 56.93 & 61.15 & 0.46 & 0.53 & 0.46 & 51.90 & 0.53 & 0.45 & 49.46 & 0.54 \\
\hline Deviation from Avg. & -0.01 & 0.02 & 1.16 & 2.34 & 0.03 & 0.02 & -0.02 & 2.52 & 0.02 & -0.03 & 2.6 & 0.02 \\
\hline \multicolumn{13}{|l|}{ Medium Watershed } \\
\hline Max. & 0.31 & 1.00 & 99.86 & 99.99 & 1.00 & 1.00 & 1.00 & 99.61 & 1.00 & 1.00 & 99.83 & 1.00 \\
\hline Avg. & 0.08 & 0.37 & 71.49 & 45.87 & 0.48 & 0.47 & 0.47 & 53.67 & 0.45 & 0.50 & 53.02 & 0.43 \\
\hline Min. & 0.00 & 0.00 & 3.42 & 1.01 & 0.00 & 0.00 & 0.00 & 1.34 & 0.00 & 0.00 & 1.34 & 0.00 \\
\hline SD & 0.05 & 0.28 & 22.39 & 27.72 & 0.29 & 0.30 & 0.29 & 27.77 & 0.30 & 0.30 & 27.91 & 0.30 \\
\hline Calibrated value & 0.08 & 0.35 & 69.53 & 43.45 & 0.45 & 0.50 & 0.45 & 56.11 & 0.48 & 0.48 & 50.57 & 0.40 \\
\hline Deviation from Avg. & 0 & -0.02 & -1.96 & -2.42 & -0.03 & 0.03 & -0.02 & 2.44 & 0.03 & -0.02 & -2.45 & -0.03 \\
\hline \multicolumn{13}{|l|}{ Large Watershed } \\
\hline Max. & 0.34 & 1.00 & 99.94 & 99.60 & 1.00 & 1.00 & 1.00 & 99.91 & 1.00 & 1.00 & 99.96 & 1.00 \\
\hline Avg. & 0.09 & 0.40 & 69.98 & 48.79 & 0.48 & 0.46 & 0.47 & 53.83 & 0.45 & 0.46 & 51.70 & 0.41 \\
\hline Min. & 0.00 & 0.01 & 1.13 & 1.38 & 0.00 & 0.00 & 0.00 & 1.54 & 0.00 & 0.00 & 1.09 & 0.00 \\
\hline SD & 0.06 & 0.29 & 23.00 & 28.98 & 0.28 & 0.30 & 0.28 & 27.05 & 0.29 & 0.29 & 28.70 & 0.30 \\
\hline Calibrated value & 0.10 & 0.38 & 72.00 & 46.25 & 0.50 & 0.48 & 0.44 & 51.46 & 0.42 & 0.44 & 54.21 & 0.39 \\
\hline Deviation from Avg. & 0.01 & -0.02 & 2.02 & -2.54 & 0.02 & 0.02 & -0.03 & -2.37 & -0.03 & -0.02 & 2.51 & -0.02 \\
\hline
\end{tabular}

\section{Results}

Rainfall-runoff was modeled using the calibrated Tank hydrologic model. The optimized parameters in the calibration stage were used as prediction coefficients for the validation period. Flow characteristics and the optimized parameters are given by catchment in Tables 2 and 3. Scatter plots of the observed and modeled discharges of the three watersheds are shown in Figures 3-5.
Table 2 Characteristics of the small, medium and large watersheds.

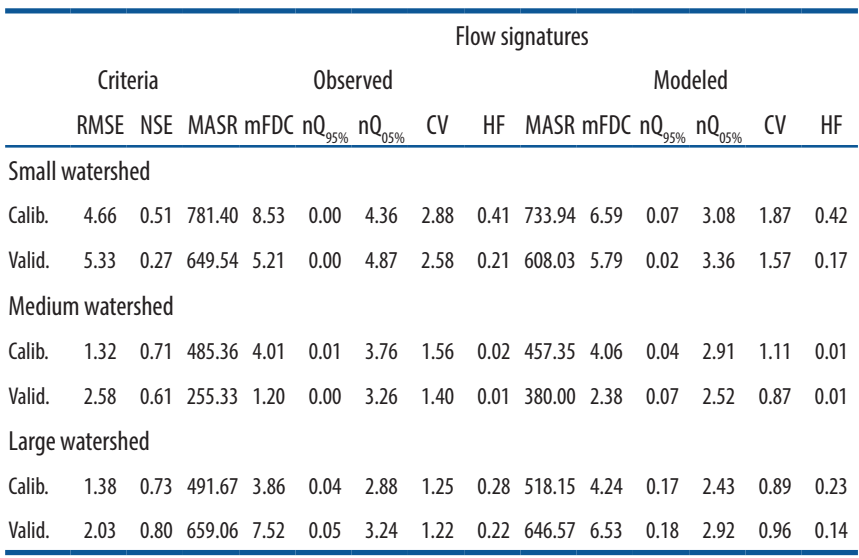

Table 3 Optimized hydrological parameters.
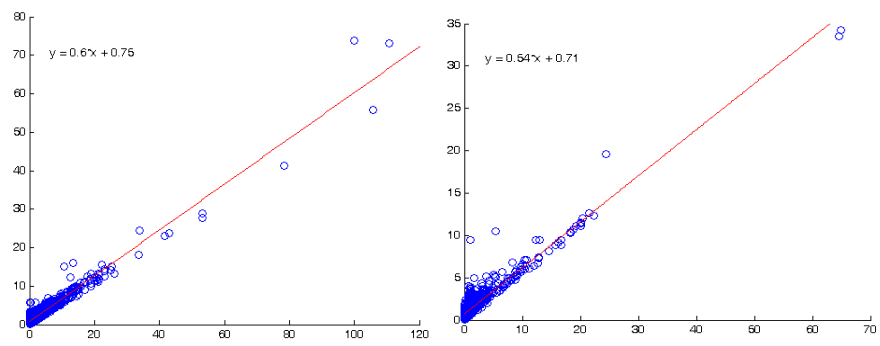

Figure 3 Neka watershed: predicted discharge vs observed discharge for calibration (left) and validation periods (right). 

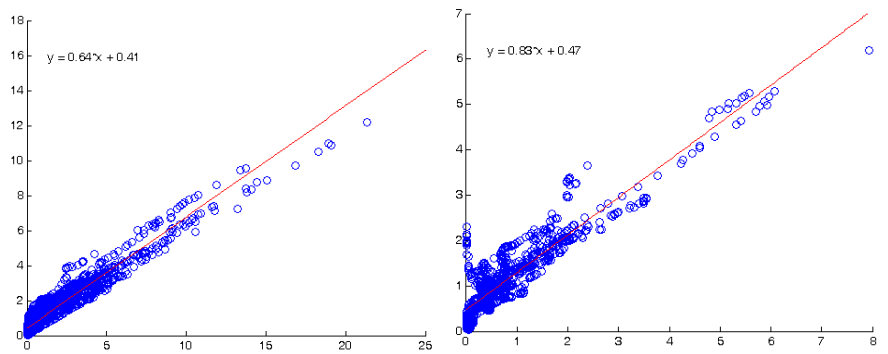

Figure 4 Ghezel-Ozan watershed: predicted discharge vs observed discharge for calibration (left) and validation periods (right).
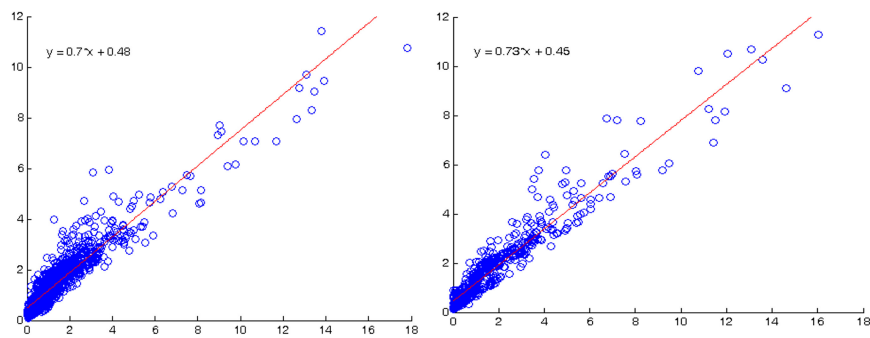

Figure 5 Babolroud watershed: predicted discharge vs observed discharge for calibration (left) and validation periods (right).

\subsection{Calibrated Parameters}

The hydrologic model was optimized for the small watershed, Neka (Table 3). Parameters related to horizontal flows (P2, P5, P7, $\mathrm{P} 10$ and $\mathrm{P} 12)$ showed satisfactory results $(-6 \%$ to $+7 \%$ relative to the average of each given parameter range), particularly those which are related to the intermediate and subsurface flows (P2). For vertical flow parameters (P1, P6 and P9), the variation was between $-7 \%$ and $+4 \%$. The least variable parameters of the group were P6 (percolation) and P9 (deep percolation). For parameters related to storage (P3, P4, P8 and P11), the range of fluctuation was from $+2 \%$ to $+6 \%$, and $P 3$ (outlet height of subbase flow from the first tank) was the most stable parameter in the group.

The model was optimized for the medium watershed (Qezel-Ozan). In general, parameters associated with horizontal flows showed variations in the range $-7 \%$ to $-4 \%$. P7 and P10 were the least variable parameters in the group. For parameters associated with vertical flow, the range of calibrated values varied from $0 \%$ to $+7 \%$. P1 was the most stable parameter of this group. The range of parameters related to the storage was $-5 \%$ to $+5 \%$. P3 was the most stable parameter of this group.

Optimization of the hydrologic model for the large watershed (Babolroud) indicated that the parameters related to horizontal flow are within $-6 \%$ to $+4 \%$ of the confidence interval ranges, and $\mathrm{P} 5$ is the most sensitive parameter of the group. The parameters related to vertical flow were within $-7 \%$ to $+11 \%$ of the confidence interval range, and $\mathrm{P} 4$ was found to be the most sensitive parameter of the group. The parameters associated with storage were in the range $-5 \%$ to $+5 \%$ of the confidence interval, and $\mathrm{P} 3$ was found to be the most sensitive parameter of this group.

\subsection{Objective Functions}

Qualitative evaluation of rainfall-runoff models was performed using a descriptive-analytic approach derived from modeling the catchment characteristics and the objective function. The accuracy of model calibration is shown in Table 2. The values of RMSE and NSE for the small, medium and large watersheds were respectively 4.66 and $0.51,1.32$ and 0.71 , and 1.38 and 0.73 . For validation, the corresponding RMSE and NSE values were 5.33 and $0.2,2.58$ and 0.61 , and 2.03 and 0.80 .

\subsection{Catchment Characteristics}

\section{Mean Annual Specific Runoff}

Table 2 shows that the highest values of MASR for the calibration period were observed in the small watershed (781.40) and the lowest for the medium watershed (485.36). The highest values for validation were 659.06 for the large watershed and the lowest were 255.33 for the small watershed. The results for MASR indicate that the best model performances were observed for the large watershed in both calibration ( $+5 \%$ compared to the observed values) and validation (-2\%).

\section{Slope of Flow Duration Curve}

The maximum values of $\mathrm{mFDC}$ for calibration were observed for the small watershed (8.53) and minimum values for the large watershed (3.86). The large watershed gave the maximum (7.52) and the medium watershed gave minimum (1.2) values for validation. The best mFDC modeling results for calibration were observed in the medium watershed (+1\% compared to the observed values) and the best results for validation were observed in the small watershed (+11\%).

\section{Normalized Low Flow Statistics}

The large and the small watersheds showed the maximum and minimum values of $n Q_{95 \%}$ for calibration, 0.04 and 0.00 respectively. The values of $n Q_{95 \%}$ for validation were 0.05 for the large watershed and 0.00 for the small and medium watersheds.

The best modeling performances were observed in the large watershed for validation ( $+300 \%$ compared to the observed values) and in the medium watershed for calibration (+260\%). There was an unspecified relationship between P10 and P12 and $n Q_{95 \%}$.

\section{Normalized High Flow Statistics}

The small watershed gave the highest values of $n Q_{05 \%} 4.36$ for calibration and 3.24 for validation. The large watershed shows the lowest values of $n Q_{05 \%}$ for both calibration (2.88) and validation (3.24).

For $n Q_{05 \%}$, the best model performances were given by the large watershed in both calibration $(-16 \%$ compared to the 
observed values) and validation (-10\%). Similar to $n Q_{95 \%}$, an unspecified quantitative relationship was found between P2 and P5 and $n Q_{05 \%}$.

\section{Coefficient of Variation}

CV was a maximum in both validation (2.58) and calibration (2.88) for the small watershed and a minimum in both validation (1.22) and calibration (1.25) for the large watershed. These findings can be explained by the land of the small watershed having the least coverage of natural ecosystems such as forest and rangeland.

The best modeling performances in calibration $(-29 \%$ compared to the observed values) and validation (-21\%) were given by the large watershed.

\section{Hydrograph Flashiness}

The maximum (0.41) and minimum (0.02) values of HF were found in calibration of the small watershed and the medium watershed. In validation, the large and small watersheds gave the highest value of HF (0.22 and 0.21$)$, while the lowest value of HF (0.01) was given by the medium watershed. The maximum value of hydrograph flashiness was unsurprising for the small watershed since land coverage is dominated by agricultural use.

The best model performance in calibration was given by the small watershed ( $+2 \%$ compared to the observed values). The best model performance in validation was given by the medium watershed (0\%).

The Tank rainfall-runoff model predicted MASR with differences of $-6 \%,-5 \%$ to $+49 \%$, and $-2 \%$ to $+5 \%$ relative to the observed values for the small, medium, and large watersheds respectively. Therefore the model has limited application in a medium sized watershed. For catchment characteristics represented by $\mathrm{mFDC}$, the results were respectively $-23 \%$ to $+11 \%$, $+1 \%$ to $+98 \%$, and $-13 \%$ to $+10 \%$ for the small, medium, and large watersheds. In terms of mFDC and MASR, the model showed limited applicability for a medium sized watershed. Due to data with zero values, it was impossible to calculate the difference as a percentage for $n Q_{95 \%}$; thus, the performance of the model cannot be assessed for this metric. The results for $n Q_{05 \%}$ showed that high flows were modeled with approximate differences of $-29 \%$ to $-31 \%$ for the small watershed, $-23 \%$ for the medium watershed, and $-10 \%$ to $-16 \%$ for the large watershed (relative to the observed values). Thus, the performance of the model is unsatisfactory with regard to this metric for small watersheds, but appropriate for a large watershed. The results for CV showed respective differences of $-35 \%$ to $-39 \%,-29 \%$ to $-38 \%$, and $-21 \%$ to $-29 \%$ for the small, medium, and large watersheds (relative to the observed values). The results suggest that the performance of the model for this metric is at the moderate to low level for all watersheds. Finally, the results for the HF index showed a difference of $-19 \%$ to $+2 \%$ for small watersheds, 0 to $-50 \%$ for medium watersheds, and $-6 \%$ to $-18 \%$ for large watersheds (relative to the observed values).

\section{Discussion}

This study was performed to investigate the suitability of the Tank model in predicting the hydrologic processes associated with rainfall-runoff in temperate and humid regions. Three watersheds (Neka, small; Qezel-Ozan, medium; and Babolroud, large) with different spatial scales were selected for study.

The Tank model was calibrated using the basic hydrologic concepts proposed by Sugawara et al. (1984), Podger (2005), and Beven and Binley (2014), and optimized using the method suggested by Setiawan et al. (2007). The model we developed uses 12 parameters associated with horizontal and vertical flows, as well as storage coefficients and specifications relevant to ecosystem characteristics such as land use, land cover, level of development and imperviousness. It models water balance using surface flow (P5), upper subsurface flow (P2), intermediate flow (P7), subbase flow (P10), and baseflow (P12, representative of environmental flow) (Sheikh Goodarzi, Navardi et al. 2018). Choosing a model with many parameters (twelve) increases uncertainty, but offers other advantages, such as having minimal data requirements and giving acceptable performance in simulating the runoff nexus, which enable us to mitigate uncertainty through optimization (Amiri et al. 2016; Setiawan et al. 2007; Podger 2005).

Comparison of flow characteristics showed that the small watershed is a marginally high flow watershed characterized by fast flow slope, low threshold of low flow, the highest threshold of high flow, together with the highest tension, the highest $\mathrm{CV}$, and a significant variable hydrograph. Although Neka is a low slope watershed, it usually becomes flashy because of high flow (due to conjoined upstream flows and lack of natural covers such as forest and rangeland). In contrast, the medium watershed (Qezel-Ozan) is characterized as a low flow watershed having low flow slope, a low threshold of low flow, a medium threshold of high flow, medium CV, and a substantial constant hydrograph. These observations for Qezel-Ozan are consistent with predominant permeable landcover (rangeland and forest), basin shape, and a very delayed concentration time. The large watershed is characterized as a medium flow watershed with medium flow slope, the highest low flow threshold, a medium high flow threshold, medium CV, and a variable hydrograph. Despite its large watershed area, Babolroud is dominated by agriculture and forest land use and land cover, which have made it completely resilient to flashy hydrologic processes.

The use of catchment characterization measures (such as flow signatures) as well as measures of model accuracy (RMSE and NSE) for watersheds at various scales led to integrated model performance analysis. Thus the results of this study provide more detailed information for land managers who have been dealing with limited data, especially in temperate regions. Generally, the quality of our rainfall-runoff model (a typical model using four permeable tanks) varies from an acceptable level for the medium and large watersheds (with areas $215 \mathrm{~km}^{2}$ and $542 \mathrm{~km}^{2}$ ) to a moderate level for the small watershed (especially during the validation period). The latter limitation depends on the water budget of 
the small watershed (high amount of inflow) and the loss of natural land cover (forest and rangeland). Consequently, this level of complexity in small watersheds cannot be truly addressed using black box tank models. The performance of the hydrologic model was further investigated using flow signatures.

In summary, the Tank hydrologic model can be applied to various spatial scales, with the limitations discussed. As the results clearly showed, the applicability of the Tank hydrologic model (as a representative lumped model) to predict rainfall-runoff-related processes can be advantageous, especially if there is limited data. Unlike sophisticated and process oriented hydrologic models that require long processing times and long data time series, the use of the Tank model with flow signatures provides a robust basis for decision making and assessment concerning the primary hydrologic impact of changes in ungauged basins. Since a large number of parameters are used in the Tank model, sensitivity analysis is recommended to reduce uncertainty. Alternatively, parameter regionalization can be an effective way to calibrate the hydrologic parameters when there is insufficient data.

\section{References}

Ahmadian, S. and M. Sheikh Goodarzi. 2014. “Performance Comparison of HBV, IHACRES and SIMHYD Hydrological Models for the Runoff Simulation (Study Area: Sefidroud River Basin, North of Iran)." Storm Water \& Urban Water Systems Modeling Conference, Toronto, Ontario, February 26-27, 2014.

http://www.icwmm.org/2014-C023-27.

Allen, R. G., L. S. Pereira, D. Raes and M. Smith. 1998. Crop Evapotranspiration Guidelines for Computing Crop Water Requirements. Rome: Food and Agriculture Organization. FAO Irrigation and Drainage Paper 56.

Amiri, B. J., N. Fohrer, J. Cullmann, J. Hörmann, F. Müller and J. Adamowski. 2016. “Regionalization of Tank Model Using Landscape Metrics of Catchments." Water Resource Management 30:5065-85. https://doi.org/10.1007/s11269-016-1469-5

Amiri, B. J., J. Gao, N. Fohrer, J. Adamowski and J. Huang. 2019. "Examining Lag-time using the Landscape, Pedoscape and Lithoscape Metrics of Catchments." Ecological Indicators 105: 6-46. https://doi.org/10.1016/j.ecolind.2019.03.050

Aqili S. W., N. Hong, T. Hama, Y. Suenaga and Y. Kawagoshi. 2016. "Application of Modified Tank Model to Simulate Groundwater Level Fluctuations in Kabul Basin, Afghanistan." Journal of Water and Environment Technology 14 (2): 57-66.

Beven, K and A. Binley. 2014. "GLUE: 20 Years on." Hydrological Processes 28 (24): 5897-918. https://doi.org/10.1002/hyp.10082

Chai, T. and R. R. Draxler. 2014. “Root Mean Square Error (RMSE) or Mean Absolute Error (MAE)? Arguments Against Avoiding RMSE in the Literature." Journal of Geoscience, Model
Development 7:1247-50.

https://doi.org/10.5194/gmd-7-1247-2014

Ekenberg, M. 2016. Using a Lumped Conceptual Hydrological Model for Five Different Catchments in Sweden. Stockholm: University of Stockholm, Physical Geography and Quaternary Geology. Master's Thesis.

Franchini, M. and M. Pacciani. 1991. "Comparative Analysis of Several Conceptual Rainfall-Runoff Models." Journal of Hydrology 122:161-219.

Haberlandt, U. and U. Radtke. 2014. "Hydrological Model Calibration for Derived Flood Frequency Analysis Using Stochastic Rainfall and Probability Distributions of Peak Flows." Journal of Hydrology and Earth System Sciences 18:353-65.

Ketabchy, M., D. J. Sample, T. Wynn-Thompson and M. N. Yazdi. 2018. "Thermal Evaluation of Urbanization Using a Hybrid Approach." Journal of Environmental Management 226:457-75. https://doi.org/10.1016/j.jenvman.2018.08.016

Khakbaz, B., B. Imam, K. Hsu and S. Sorooshian. 2012. “From Lumped to Distributed via Semi-distributed: Calibration Strategies for Semi-distributed Hydrologic Models." Journal of Hydrology 418-419:61-77.

Nash, J. E and J. V. Sutcliffe. 1970. "River Flow Forecasting Through Conceptual Models, Part 1: A Discussion of Principles." Journal of Hydrology 10:282-90.

Ou, X., B. Gharabaghi, E. McBean and C. Doherty. 2017. “Investigation of the Tank Model for Urban Storm Water Management." Journal of Water Management Modeling 25: C421. doi: 10.14796/JWMM.C421.

Patil, S. and M. Stieglitz. 2014. "Modeling Daily Streamflow at Ungauged Catchments: What Information Is Necessary?" Hydrological Processes 28:1159-69. https://doi.org./10.1002/hyp.9660

Podger, G. 2005. “Rainfall Runoff Library (RRL)." In Catchment Modeling Toolkit prepared by the CRC for Catchment Hydrology, Australia.

Reed, S., V. Koren, M. Smith, Z. Zhang, F. Moreda and D. J. Seo. 2004. “Overall Distributed Model Intercomparison Project Results." Journal of Hydrology 298:27-60.

Setiawan, B. I., Rudiyanto, U. Ilstedt and A. Malmer. 2007. Optimization of Hydrologic Tank Model's Parameters. Umeå, Sweden: Swedish University of Agricultural Sciences, Department of Forest Ecology.

Sheikh Goodarzi, M. 2013. "General Review of Ecosystem Based Hydrological Modeling Techniques." Ph.D. Seminar, Department of Environment, University of Tehran, Iran.

Sheikh Goodarzi, M., B. Jabbarian Amiri and H. Azarnayvand. 2018. "Investigating Performance of the Conceptual Models in River Hydrologic Simulation." Journal of Natural Environment 71 (4): 509-21 (abstract in English).

Sheikh Goodarzi, M., S. Navardi and B. Jabbarian Amiri. 2018. "Evaluation of Different Calibration Strategies for 
Rainfall-Runoff Modeling Using Tank Hydrological Lumped Model." 13th International Conference on Hydroinformatics, HIC2018, Palermo, Italy. https://doi.org/10.29007/66vq

Sugawara, M., I. Watanabe, E. Ozaki and Y. Katsuyama. 1984. Tank Model with Snow Component. Tokyo: National Research Center for Disaster Prevention. Research note no. 65.

Sugiura, A., S. Fujioka, S. Nabesaka, M. Tsuda and Y. Iwami. 2016. "Development of a Flood Forecasting System on the Upper Indus Catchment Using IFAS." Journal of Flood Risk Management 9 (3): 265-77.

https://doi.org/:10.1111/jfr3.12248

USGS (U.S. Geological Survey). 2008. Calculating Flow-Duration and Low-Flow Frequency Statistics at Streamflow-Gaging Stations. Washington, DC: U.S. Department of the Interior. Scientific Investigation Report 2008-5126.
Verstraeten W. W., B. Muys, J. Feyen, F. Veroustraete, M. Minnaert, L. Meiresonne and A. De-Schrijver. 2005. "Comparative Analysis of the Actual Evapotranspiration of Flemish Forest and Cropland Using the Soil Water Balance Model WAVE." Journal of Hydrology and Earth System Sciences 9:225-41.

Viglione, A., J. Parajka, M. Rogger, J. L. Salinas, G. Laaha, M. Sivapalan and G. Blöschl. 2013. “Comparative Assessment of Predictions in Ungauged Basins, Part 3: Runoff Signatures in Austria." Journal of Hydrology and Earth System Sciences 17:2263-79. 